\title{
Applying the Bologna Principles in an Information Science Course
}

\author{
Jadranka Lasic-Lazic, Marija László and Damir Boras Professors Croatia
}

\section{Summary}

The paper deals with a pilot evaluation of comprehensive reading skills of 30 students studying information science at the Faculty of Philosophy, University of Zagreb. After having read a freely chosen article from information science journals, the participants were interviewed using a questionaire in written form. The answers were examined by researchers, classified and evaluated with the respect to the degree of the students' comprehension of the articles. It has been found that their understanding is incomplete, and therefore attention should be devoted to teaching an introductory course on how to make use of reading material in order to acomplish fuller understanding of scientific articles.

\section{Introduction}

The hypothesis is that the students in the Departement of Information Science at the Faculty of Philosophy, University of Zagreb, who have passed the classification exam after having graduated from highschool, possess sufficient reading skills in order to be able to follow the lectures, exercises, seminars and write term papers based on library resources. It is assumed that the students are prepared to comprehend reading materials without special instructions. They are supposed to know how to learn facts and concepts in information science, computer science, social studies, behavioral sciences, and other related subjects through reading.

Working with the students, reading their term papers, and examining them often reveals that the reading materials is not understood completely. In most cases the subject of the articles read are retold using the same vocabulary without applying a broader context, or linking with similar fields. 
Reading comprehension is explained by some educators as a series of subskills. They include skills like understanding word meaning in context, making inferences about information implied, finding the main idea, and distinguishing between facts and opinion. Reading materials become more abstract in high school and college and contain more technical vocabulary. At that stage the students must not only acquire new information but also they must critically analyze the reading materials. They must achieve an optimal reading rate that is based on the difficulty of the material and the purpose of the reading.

An attempt to test students' skills at comprehensive reading and understanding scientific reading materials involving a certain amount of critical thinking was made. A population of 30 students was instructed to choose freely an article in an information science journal and read it carefully. Then they were interviewed and asked to write a term paper answering relevant questions about the subject.

\section{Objectives}

It is well known that scientific journals have their specific literary style, which does not often occur in other publications. The purpose of a scientific article is to communicate the scientific findings as clear as possible using highly stylized expressions and specific vocabulary. For the applied professionals, not only for the students, it is sometimes difficult to grasp all that an article offers.

The structure of a scientific article is in most cases standardized. It usually begins with an Abstract that summarizes the subject. Next there is usually an introductory part where the Purpose, Problems, Hypotheses elaborated in the study are defined. The Methods \& 
Procedures section explains why, what, where, and how the study was performed. The final parts of a scientific article usually include the Results, Discussion and Conclusions. The results require more detailed explanations. The Discussion and Conclusions sections explain, discuss and conclude the achievement of the findings and compare these findings with other studies in the same field or related ones.

The experienced reader of a scientific article is challenged to evaluate the methodology in order to best ascertain the credibility of the study. Students might not reach that level but they can be made aware of the difficulties. They should also improve their vocabularies by paying attention to any new term or word, or find the meaning of a word from the context. They can try to develop an awareness of the main points and details of a selected and carefully read article.

In a pilot study, we wanted to find out if the students have understanding and interpretation problems with some specific parts of a scientific article. At the beginning level of the project, the students were asked to choose for reading an article from an information science journal. After having read it carefully, they had to photocopy it and attach to their term paper. The titles of the journals and their ISSN are given in an asterisked note at the end of this paper after References. In their term paper, they had to write a short overview of the subject of the article, supply bibliographic citations, and answer the following main questions and subquestions to supply data for statistical processing.

\section{Questionnaire}

1. Title. Was the subject of the article clearly expressed in its title?

2. Purpose. What was the purpose of the introductory part of the article?

3. Problems. What did you learn from its introductory section?

4. Hypotheses. What was the problem or the question that was studied (or what were the hypotheses of the study)?

5. Methods\&Procedures. What is the theoretical base of the study? 
6. Results. What is the result of the study? What were the data and how are they presented?

7. Discussion. What is said in the discussion section of the article? Are there some assumptions about the pratical applications of the study?

8. Conclusion. What is the achievement of this study in the field of information science?

9. Abstract. Did you meet your expectations about the value of the article because you selected it for reading?

The statistical survey of the 270 answers to the 9 questions follows in a tabular form.

\section{Procedures}

The answers were examined, classified, counted, and together with the questions presented in the Table. The table consists of ten columns. In the first column with the heading Question, the ordinal number of the question is given as explained in the preceeding section of this article entitled Objectives. The second column called Section contains the ideal composition of the article. The items in this column refer to the questions enumerated in the Questionnaire. The Title (row 1) of an article is supposed to point to the subject of it. The Purpose (row 2) deals with the objective of the research. The Problems (row 3) comprises the questions to be considered, solved or answered and may be accompanied with some theoretical explanations. The Hypotheses (row 4) is an assumption on something to be investigated. The Methods \& Procedures (row 5) section elaborates the theory on which the research is based. The Results (row 6), Discussion (row 7), and Conclusion (row 8) sections facilitate the evalution. The column ends with the Abstract (row 9).

The answers to our questions were given verbally. They are summarized in four categories in columns 3 to 6 according to the questions indicated by their numbers in rows 1 to 9 . If a particular answer was considered affirmative by the researcher on the basis of the written explanations given by the subject of the research, it was counted as Understood\&explained in column 3. If the answer was vague without any explanation, it was registered under the 
category Vague or not understood. Columns 5 \& 6 Not sure and No answer are self-

explanatory.

The classification of the answers into categories had to be as homogeneous as possible to enable detection of differences between them. It had to be established which elements in this research on understanding a scientific article are easier to understand and which are more difficult.

\section{Table}

\begin{tabular}{|c|c|c|c|c|c|c|}
\hline 1 & 2 & 3 & 4 & 5 & 6 & 7 \\
\hline Question & Section & $\begin{array}{c}\text { Understood\& } \\
\text { Explained }\end{array}$ & $\begin{array}{c}\text { Vague or } \\
\text { not } \\
\text { understood }\end{array}$ & $\begin{array}{c}\text { Not } \\
\text { sure }\end{array}$ & $\begin{array}{c}\text { No } \\
\text { answer }\end{array}$ & $\begin{array}{c}\text { Number } \\
\text { of } \\
\text { students }\end{array}$ \\
\hline 1 & Title & 20 & 10 & 0 & 0 & 30 \\
\hline 2 & Purpose & 30 & 0 & 0 & 0 & 30 \\
\hline 3 & Problems & 24 & 6 & 0 & 0 & 30 \\
\hline 4 & Hypotheses & 10 & 7 & 13 & 0 & 30 \\
\hline 5 & Methods\&Procedures & 20 & 3 & 7 & 0 & 30 \\
\hline 6 & Results & 15 & 8 & 0 & 7 & 30 \\
\hline 7 & Discussion & 15 & 8 & 0 & 7 & 30 \\
\hline 8 & Conclusion & 24 & 0 & 6 & 0 & 30 \\
\hline 9 & Abstract & 15 & 10 & 5 & 0 & 30 \\
\hline
\end{tabular}




\section{Results}

The population of 30 individuals in the pilot study makes it possible to apply some statistical measures based on the so called nominal scale. However, the study falls short compared to a full scale statistical analysis based for instance on larger population, application of numerical measuring tools in addition to verbal, objective evaluation of collected answers following predefined criteria. The aim is to prove or disprove our hypothesis that the students will have some problems with understanding and interpretation of an scientific article. Objectionable shortcomings of the current study from the statistical point of view may be that it dealt with the smallest statistically feasable number of individuals involved. Another objection could be that the instrument (questionnaire) for the data collection was not elaborated enough and also that no numerical scale was used to make the processing of responses more precise and reliable.

Since classification is fundamental to any science, all other levels of measurement, no matter how precise, basically involve classification as a minimal operation. That is why classification is to be considered the lowest level of measurement in the broadest sense of the term. The names assigned to the categories in columns 3 to 6 serve as a nominal scale suitable for research on comprehensive reading of a scientific article.The term nominal scale as is used here refers to the simplest level of measurement and constitutes the minimal condition necessary for the application of numeric statistical procedures.

The nominal scales enable the use of the basic arithmetic operation, that is, counting the number of cases within each category so that it is possible to numerically process the number of answers in each of the four categories in Table: Understood \& Explained column three, Vague or not understood column four, Not sure column five, and No answer column six.

The categories are mutually exclusive and exhausted, i.e., each answer given by the participants is placed in one and only one category. There are 30 answers for each question and the answers are distributed into four categories as presented in Table. We can then use the proportion of answers in any given category. The proportion is defined as the number of 
answers in the relevant category divided by the total numbers of answers (30). Expressing the data in terms of proportions makes it posssible to perform a direct comparison among rows (questions) and columns (answers). A better overview is obtaind if the Table is transformed into a chart

\section{Chart}

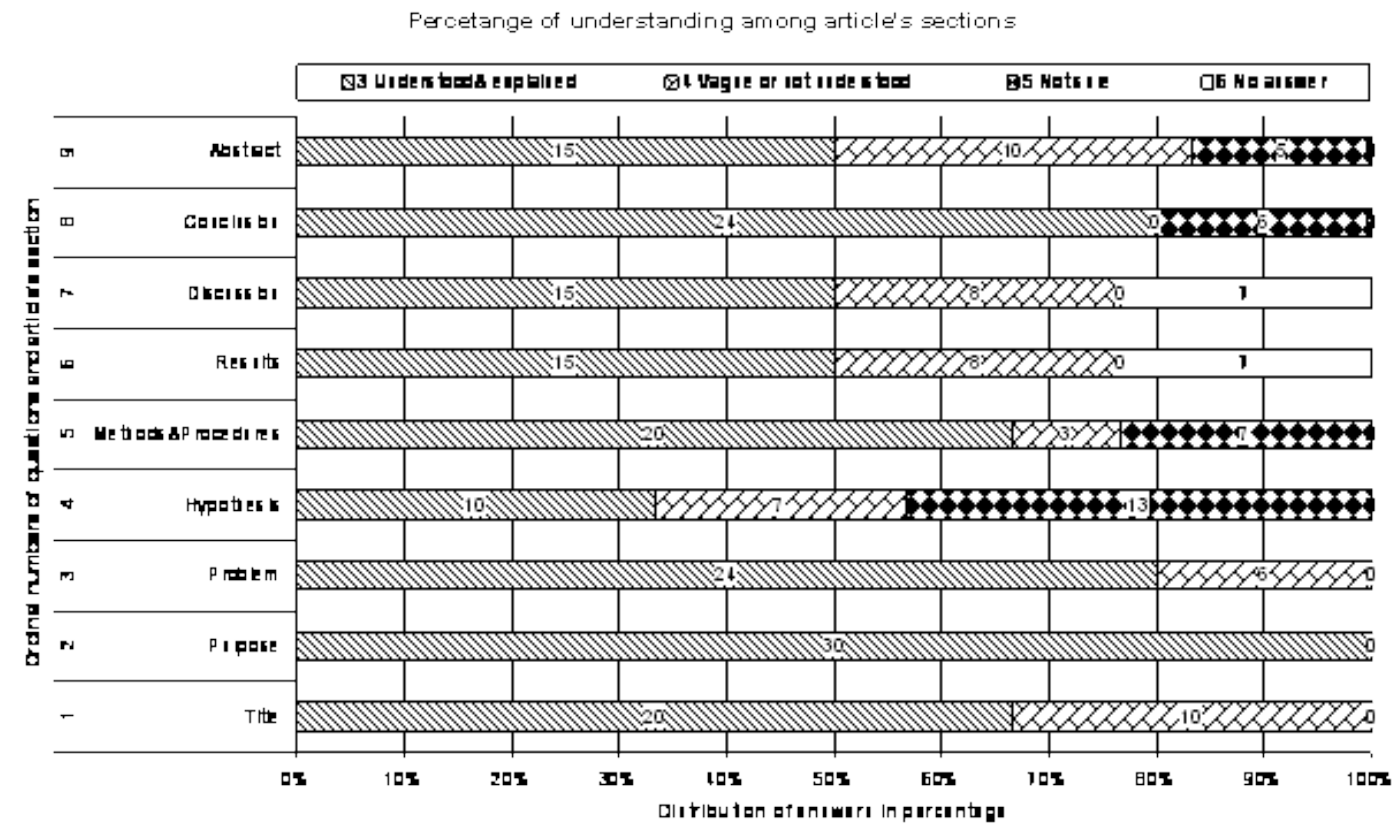

The chart represents each question and the answers to it in two forms. Their actual number is indicated in the corresponding shaded bar. However evaluating their percentage with respect to the total may turn out to be more complicated. It is obtained by computing the difference between the abscissas of the points belonging to the vertical projections onto the bottom line of the initial and end points of the bar.

Each horizontal bar has its number (1 to 9) reflecting the ordinal number of the corresponding question. The names of the sections of the article are placed on the left side of the bars that the questions refer to. The shadings in each bar help visualizing the percentages (proportions) of the answers indicated on top of the chart bellow the title. If the section of an article was understood and explained, then the shading for that category is dominant (see bars 2, 5, 8). 
For instance, the introduction about the Purpose of an article (bar 2) was completely understood and explained as shown by uniform shading (100\%). The Conclusion (bar 8) was understood and explained by the group of students in the amount of $80 \%$ to be read on the horizontal axis at the bottom of the chart. The Title (bar 1) of an article and the Methods \& procedures (bar 3 ) were understood by $65 \%$ percentage of participants. $50 \%$ of the students understood the Results section (bar 6), the Discussion (bar 7) and the Abstract (bar 9) of the articles processed. The Hypotheses section (bar 4) was the most difficult to understand. It turned out to be understood approximately by $30 \%$ of the participants only, while $70 \%$ of them admitted that they were either Not sure or Vague or not understood.

The part of the table concerning the article comprehension may be illustrated more graphically using the polar coordinate system displayed in the Graph below. To facilitate readings of the values, the relevant radii are drawn, as if they were spokes, on the background of a cobweb. The Graph has been created by connecting points on the radii corresponding to the classification of the questions Understood \& Explained, Vague or not understood, Not sure, and No answer. The conection lines border four shaded areas displayed in the Diagram.

The background of the Graph has nine sides, nine vertices, and nine scaled radii (the spokes). The nine-sided polygon contains nine smaller similar polygons following the scales on the radii. The distance of these points from the center shows the number of participants who understood the particular question and can be read on the vertical ordinate axis at vertex 1 named Title. The diagram vertices are marked with the numbers of the questions and section names read clockwise from the topmost vertex (1 Title). The distance between polygons is graded by five representing five participants on the vertical axis.

The top vertex 1 Title reaches the value 20 participants on the graded scale. Vertex 2 Purpose reaches 30 participants. The other values can be read on the intersection of the particular radius with the border line of a certain shaded area. These shaded areas actually specify how much of the article was understood and the white areas indicate how much of it was not. If every part of it was understood, the shaded area would fill the whole diagram.

\section{Graph}


Connected point diagram

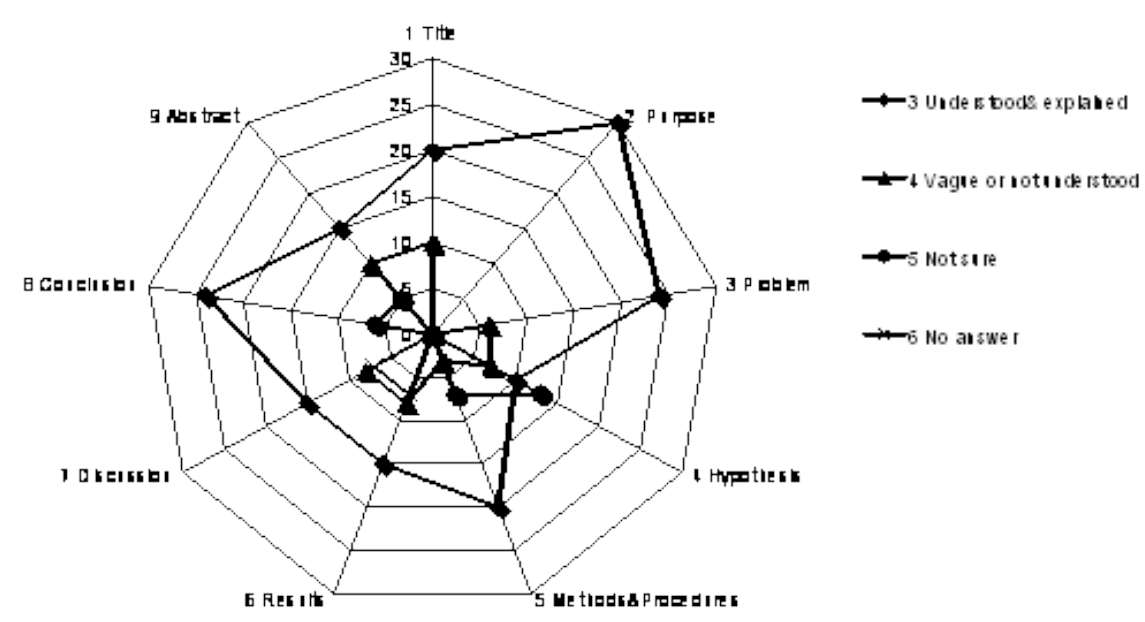




\section{Diagram}

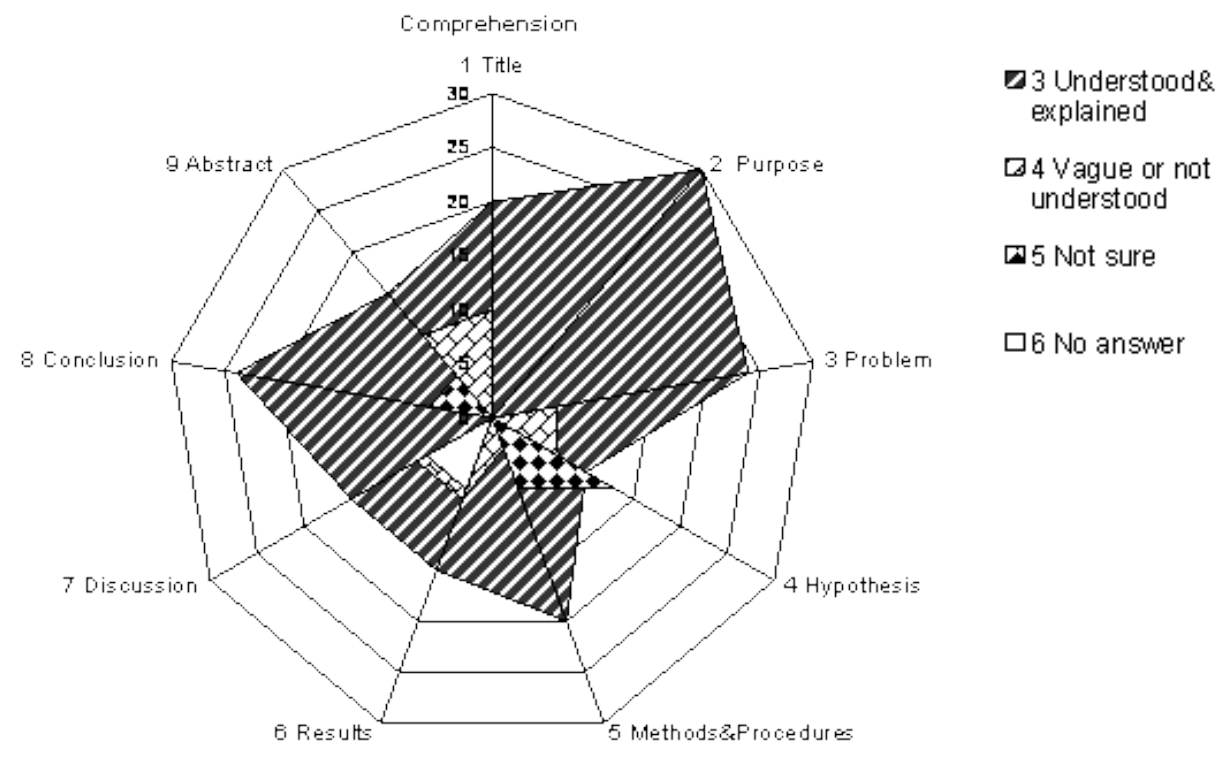

Using the Diagram representation it can be detected how many students had difficulties in grasping their articles. If the top of a certain intersection of areas marked in the legend is closer to the center of the Diagram, it points to a smaller number of students involved, e.g. the intersections on vertex 4 indicate that the Hypothesis was Understood (see legend 3) by 10 students, Vague (legend 4) by 13, Not sure (legend 5) by 7. In the same way we can interpret the intersections on the other vertices, such as 6 Results, 7 Discussion and 9 Abstract.

\section{Conclusion}

In summarizing data by substituting very few measures for many words in the answers elicited from the examinees, certain information is inevitably lost. What is even more serious, it is very possible to obtain results which are misleading unless cautiously interpreted. Therefore, we are aware that the limitations of our summarizing measures must be clearly indicated. First of all, the students read different articles, not the same one. The questions were general in order to get insight on scientific article understanding. The anwers of the 
examinees were descriptive and we had to interpret them subjectively. Statistical inference performed on the basis of these results may not be statistically reliable. Nevertheless it can still be useful for analyzing which sections of a scientific article were the most difficult part of the articles to the examinees.

Despite of weaknesses, the results can be instructive for orientation in devising curricula to make the students aware of how to make use of a reading material in order to acomplish fuller understanding of scientific articles. Relevant scientific concepts have to be introduced with more details and examples. Therefore a highly sophisticated statistical analysis may be an aid to, but never a substitude for, good sound thinking.

\section{References}

Blalock M. B. Jr. (1979). Social statistics (2nd ed.). New York : McGraw Hill.

Gay, L. R. (1987). Educational research: Competencies for analysis and application (3rd ed.). New York: Merrill.

Kravitz Len (2005). Understanding and enjoying research. IAFC Conference Report: Reading and Interpreting Research.

http://www.unm.edu/ 1kravitz/Article\%20folder/understandres.html (2005-04-01).

\section{Journals Offered}

* Informatica museologica ISSN 0350-2325, Informatologija ISSN 1330-0067, Jasis Journal of the American Science ISSN 0002-8231, Journal of Documentation ISSN 0022-0418, Journal of Education, Journal of Education for Librarianship ISSN 0022-0604, Journal of Education for Library and Information Science ISSN 0748-5786, Journal of the American Society for Information Science and Technology ISSN 1532-2882, Knjižnica ISSN 00232424, Muzeologija ISSN 0353-7552, Vjesnik bibliotekara Hrvatske ISSN 0507-1925. 